\title{
GÊNERO E TRABALHO: AS RELAÇÕES ENTRE TRABALHADORES DE UMA EMPRESA TRANSNACIONAL, A PARTIR DAS NARRATIVAS DE SEUS EMPREGADOS
}

\author{
Cátia Regina Muniz ${ }^{1}$
}

\begin{abstract}
Resumo: Este artigo propõe-se a analisar as relações entre trabalhadores e trabalhadoras de uma empresa transnacional, a partir das narrativas de um casal que trabalhou na mesma nas décadas de 40 e 50 . O relato do referido casal permitiu a realização de comparações com dados obtidos em pesquisa anterior (2001) em uma fábrica pertencente à empresa em questão. Nas relações destacam-se a divisão sexual do trabalho e o caráter sexual como mecanismos simbólicos de exclusão das mulheres, principalmente as operárias, das fábricas pesquisadas, cujo intuito era o de manter a "supremacia masculina" na área produtiva.
\end{abstract}

Palavras-chave: Gênero, trabalho, narrativas, relações, divisão sexual do trabalho, exclusão

\begin{abstract}
This article considers analyzing it the relations between workers and workers of a transnational company, from the narratives of a couple that worked in the same one in the decades of 40 and 50. The story of the related couple allowed the accomplishment of comparisons with data gotten in previous research (2001) in a pertaining plant to the company in question. In the relations they are distinguished it sexual division of the work and the sexual character as symbolic mechanisms of exclusion of the women, mainly the laborers, of the searched plants, whose intention was to keep the "masculine supremacy" in the productive area.
\end{abstract}

Keywords: Gender, work, narratives, relations, sexual division of the work, exclusion

1 Pesquisadora de Pós-Doutorado do Departamento de Sociologia, do Instituto de Filosofia e Ciências Humanas - IFCH, da Universidade Estadual Campinas, Unicamp, financiada pela FAPESP. 
| 190 |

Gênero e trabalho: as relações entre...

\section{Introdução}

O intuito deste artigo é discutir as relações, especificamente nas décadas de 40 e 50, entre trabalhadores e trabalhadoras de uma empresa ${ }^{2}$, pertencente a um grupo anglo-holandês, que se estabeleceu no Brasil, na capital do Estado de São Paulo, em 1929. A escolha do período analisado se deu durante as entrevistas a um $\operatorname{casal}^{3}$ (Sr. José e D. Maria) que havia trabalhado na fábrica deste grupo localizada na cidade de Valinhos-SP. As narrativas deste casal evidenciaram situações que se aproximaram do que observei em outra pesquisa (Muniz, 2001a) na fábrica do mesmo grupo situada na cidade de Vinhedo - SP, acerca do caráter sexual, que caracterizava o relacionamento entre operários e operárias, de ambas as fábricas.

A empresa em questão surge de uma fusão entre uma empresa anglo-holandesa e a sua principal concorrente no ramo de produtos de limpeza e higiene, nos segmentos de sabões, sabonetes e creme dental, localizada na cidade de Valinhos no interior de São Paulo, em 1960. A integração entre estas empresas, segundo texto elaborado pela companhia, necessitou de alguns anos, devido à rivalidade entre ambas. Superados os problemas iniciais, a empresa efetuou uma série deinvestimentos, os quais contribuíram para consolidar sua posição no mercado, diversificando seus produtos (inserindo a produção de alimentos, por exemplo. Esta diversificação fez com que a fábrica de Valinhos, na década de 70, se dividisse em três áreas: de sabonetes, sabões e saponáceos (Divisão de Sabonetes e Detergentes com fábricas localizadas em Valinhos e Indaiatuba, ambas em São Paulo; Igarassu em

\footnotetext{
${ }^{2}$ Manterei o nome da empresa em sigilo, devido ao pedido da mesma.

${ }^{3}$ Utilizarei nomes fictícios para não revelar a identidade dos sujeitos da pesquisa, os quais foram entrevistados para a elaboração da minha tese de doutorado, intitulada "As representações sobre o trabalho a partir das narrativas de uma família de operários", defendida no Instituto de Filosofia e Ciências Humanas - IFCH, da Universidade Estadual de Campinas, Unicamp, em dezembro de 2006.
} 
Pernambuco); de creme dental, talco, perfumaria, xampu, creme hidratante e de cabelo (Divisão de Produtos Pessoais com fábricas localizadas em Vinhedo - SP e Recife- PE) e de margarinas e outros produtos alimentícios (Divisão de Alimentos, com fábricas em São Paulo e Minas Gerais).

No ano de 2001 realizei uma pesquisa de dissertação de mestrado sobre questões de gênero, na fábrica em Vinhedo $\mathrm{SP}$, na qual verifiquei que no período da década de 70 , data da inauguração desta fábrica, até os anos 90 nunca houvera separações entre as relações pessoais e profissionais na empresa. Este fato chamou minha atenção, me instigando a investigar melhor o assunto. As entrevistas e observações mostraram que em 1994, devido a resultados negativos no faturamento da empresa, que teve como uma de suas justificativas os relacionamentos pessoais entre os trabalhadores, fizeram com que a administração desta fábrica fosse substituída. Conforme Barbosa (1996/97), quando a fábrica apresentava maus resultados no negócio este era atribuído, pelas outras divisões, à existência das festas: "A existência da festa funcionava como pólo contrastivo negativo e englobava quaisquer aspectos positivos do negócio". (Barbosa, 1996/97, p. 20).

Desse modo, com a finalidade de desconstruir esta imagem negativa, o novo administrador resolveu tomar algumas medidas, tais como; proibição de namoro entre trabalhadores e trabalhadoras, e, particularmente, as festas - com exceção daquelas destinadas à confraternização no final do ano e festas juninas.

No passado, período anterior ao ano de 1994, esta fábrica era caracterizada como festeira, famosa por suas festas, informal, divertida, superficial, elitista, glamorosa, cheia de nomes famosos e de pessoas interessantes (Sadia, Matarazzo, etc.), que sabiam se divertir, e que mantinham pouca distinção entre o profissional e o pessoal, de acordo com dados em relatório elaborado por Lívia Barbosa (1996/97), e confirmado por trabalhadores e trabalhadoras entrevistados. A divisão de Produtos Pessoais era denominada e ainda continuava sendo, de acordo com alguns relatos, o "barco do amor", ou seja, "todo mundo tinha caso com todo mundo". (Barbosa, 1996/97, p. 17). Em um dos relatos mencionados por 
| 192 |

Gênero e trabalho: as relações entre...

Barbosa (1996/97) uma trabalhadora comenta que havia ensaios de peças de teatro, realizadas por trabalhadores e trabalhadoras, que acabavam conduzindo os participantes a outras coisas. Conforme esta empregada da fábrica, "loucuras aconteciam depois do teatro. Aí você acordava na cama de não sabe quem..." (Barbosa, 1996/97, p. 17).

Para Barbosa (1996/97), a Divisão de Produtos Pessoais no passado aparece, metaforicamente falando, como uma figura feminina ambígua:

\begin{abstract}
A ambigüidade nasce da combinação dos aspectos positivos associados a uma mulher- divertida, glamorosa, sensual, festeira- com aspectos negativos, que tornam uma mulher vulnerável no seu caráter: pouco séria (muitos casos, misturando vida privada com o trabalho); caprichosa (decisões paternalistas); pouca efetividade (trabalho, investimento com pouco retorno); instável e superficial nos seus procedimentos. (Barbosa, 1996/97, p. 19).
\end{abstract}

É muito interessante a metáfora da mulher utilizada por Barbosa para definir esta Divisão no passado, porque apesar de todas as mudanças realizadas a partir de 1994, ainda pôde-se perceber, em 2001, que havia alguns elementos desse passado, citados por esta pesquisadora, que poderiam explicar o incomodo das trabalhadoras da fábrica estudada, quanto ao que elas chamaram de "cantadas". . As festas deixaram de existir, a empresa passou a prosperar, mas permaneceu a questão da "mistura" entre o profissional com o pessoal, por meio das "cantadas", que é o que tentarei relacionar com os dados narrados na fábrica em Valinhos em décadas anteriores.

\footnotetext{
${ }^{4}$ As "cantadas" foram descritas pelas operárias desta fábrica, como um comportamento típico de seus colegas de trabalho de elogios aos seus atributos físicos, que as incomodavam e acreditavam que tais atitudes eram utilizadas para inferiorizá-las na área produtiva.
} 
Embora tenha havido a tentativa em desmistificar a figura de "festeira" da fábrica, a representação que ainda se fazia era de uma empresa não profissional. Na concepção de uma trabalhadora da área administrativa, se alguém perguntasse a um gerente da divisão de Produtos Pessoais (Vinhedo) como foi encaminhada uma determinada reunião, este respondia: "Foi uma festa!" No entanto, se fizessem a mesma pergunta para um gerente da divisão de Sabonetes e Detergentes (Valinhos), por exemplo, este respondia que a reunião foi realizada a contento, atingindo os objetivos propostos, marcando a diferença entre uma empresa séria e outra não tão séria.

Uma coordenadora da área de Recursos Humanos, que trabalhou na divisão de Sabonetes e Detergentes, considerava o trabalho, na divisão de Produtos Pessoais, mais informal, pois podiam falar com qualquer nível hierárquico. Esta coordenadora comentou que havia um lado bom e um lado ruim de toda essa informalidade. A boa era facilitar a aproximação entre as pessoas; a ruim era que alguns trabalhadores acabam cometendo certos abusos no que se refere às "coisas" que necessitavam serem documentadas, já que estas ficavam apenas nas palavras, sem registros. Com essa informalidade alguns trabalhadores - aqui a entrevistada quis dizer apenas os homens - achavam que podiam "brincar mais". Muitos trabalhadores interpretavam estes tipos de brincadeiras, tais como "cantar" as colegas de trabalho, como uma maneira de serem aceitos no grupo, ficavam com medo de serem excluídos se não agissem da mesma forma, como afirmou um dos entrevistados da área administrativa. Esta necessidade de pertencer a um grupo que obrigam seus membros a aderirem aos mesmos ideais sociais se assemelha ao que Norbert Elias (1987) comenta sobre os nobres franceses que tinham o intuito de se diferenciar, distinguindo-se dos que não faziam parte do seu grupo, assim como, a conduta, dos estabelecidos em relação aos outsiders, descrito por este mesmo autor em sua pesquisa em uma comunidade de periferia urbana denominada Winston Parva, na Inglaterra. Elias (2000) observou que havia, nessa comunidade, uma povoação de classe trabalhadora, "estabelecida desde longa 
| 194 |

Gênero e trabalho: as relações entre...

data", que tratava "todos os recém-chegados" como pessoas que não se inseriam no grupo, como "os de fora". O relato deste trabalhador mostra certo receio por parte dos trabalhadores recémchegados em serem excluídos deste grupo, por isso reproduziam seus comportamentos em relação às trabalhadoras.

De posse dessas informações, com o intuito de elaborar uma comparação entre os dados obtidos em ambas as fábricas (Valinhos e Vinhedo), as quais pertencem ao mesmo grupo, questionei D. Maria e o Sr. José, durante entrevistas para minha tese de doutorado, sobre as relações entre homens e mulheres na fábrica, à época em que trabalharam em Valinhos, como será descrito a seguir.

1. As relações entre operários e operárias nas décadas de 40, 50, 70 e os anos 2000: as inter-relações entre passado e presente

A metodologia utilizada, na tese de doutorado, baseou-se nos recursos metodológicos de história de vida e narrativas destacados tanto por Gagnebin (1994), como por Kofes (1994 e 2000) e Piscitelli (1993), visto que, partiu-se do pressuposto, de que a idéia de narrar as reestruturações produtivas implementadas, pela empresa em questão, a partir de seus trabalhadores, possibilitaria entender melhor as transformações atuais pelas quais a empresa estava passando. As narrativas destes trabalhadores, já aposentados, possibilitaram compreender o comportamento observado, na pesquisa de mestrado, que não se restringia a uma fábrica, mas refletia a imagem que a sociedade construiu sobre a mulher trabalhadora.

Um dos meus entrevistados, o Sr. José, nasceu na cidade de Valinhos, estava como 83 anos, à época da entrevista, em 2006, e descendia de uma família italiana, entretanto, não se recordava de qual região eles vieram. Começou suas atividades na fábrica localizada em Valinhos em 1943, na produção de sabões, saindo em 1974, permanecendo nesta por trinta e um anos.

Ao longo das entrevistas, o Sr. José comentou que ouvia muitas histórias de namoro na fábrica, porém nunca presenciou 
nada que pudesse narrar, todavia, sua esposa vivenciou algumas situações enquanto operária da fábrica, na década de 60 , que merecessem destaque:

\begin{abstract}
Eu trabalhei só cinco meses, eu trabalhei no creme dental. No creme dental, e no creme dental também era aquela pilhas de caixinha, que a gente tinha que apertar elas e fechar tudo, daí o creme dental vinha tudo junto, um encostado no outro, às vezes tinha três, eu pegava um e... Punha na caixinha e fechava a caixinha, soltava na correia que ia andando. Para subir no creme dental tinha que subir escadas, era no segundo andar, para cima, então e também tinha, para por o creme dental dentro do... A coisa lá para mexer o sugo, a moça tinha que subir na escada, eles ficavam tudo embaixo olhando.
\end{abstract}

De acordo com a narrativa de D. Maria, era costume dos trabalhadores ficarem olhando por debaixo das saias de suas colegas de trabalho, enquanto estas subiam as escadas para preparem os produtos a serem misturados para a fabricação de creme dental. Lembra-se que, certa vez, seu marido, o Sr, José, contou a ela que o seu chefe o chamou para ver as trabalhadoras: "O seu Zé, venha, venha ver as meninas bonitas, vamos ver". Era chefe, mas até chamava para ir em turma espiar; ele falava espiar, a gente falava: ele vem olhar para me espiar.

Esta questão também é abordada por Silva (1996), ao pesquisar a construção da memória e as lembranças de moradores da cidade de Belo Horizonte. Esta pesquisadora mostra que esta imagem da mulher, como algo cujos atributos sexuais não só podem como devem ser "apreciados", não se limitava aos moradores e trabalhadores da cidade de Vinhedo e Valinhos. Em um dos depoimentos coletados por esta pesquisadora, há o relato de uma senhora sobre uma das praças da cidade de Belo Horizonte, na qual no final dos anos 40, mulheres casadas não podiam passear, pois nesta praça localizava-se um bar, cujos freqüentadores ficavam naquele local apenas para observar as pernas das moças 
que entravam nos bondes. Atitude muito semelhante à relatada por D. Maria e Sr. José sobre o comportamento dos trabalhadores e seus respectivos chefes em relação às operárias.

Ao questionar D. Maria sobre a reação dela e de suas colegas a este tipo de conduta por parte dos trabalhadores, esta conta que elas acabavam se acostumando com a situação a tal ponto de não mais se importarem.

Tanto no depoimento coletado por Silva, como nas narrativas acima, este procedimento aparece como comum à época e, portanto, não criticado ou mesmo discutido. Conforme Besse (1999), a submissão das classes trabalhadoras e a submissão das mulheres de todas as classes sociais constituíram-se como metas corporativas do Estado, o qual propagava a educação destas para aceitarem a dominação masculina e sua subordinação a essa dominação que sobreviveu por várias décadas, "até que a entrada maciça das mulheres de classe média na força de trabalho remunerada e o acesso às pílulas contraceptivas solapassem as coerções materiais sobre o que se apoiava". (Besse, 1999, p. 12).

Esta propaganda produzida pelo Estado, citada por esta autora, bem como, as campanhas políticas utilizadas para silenciar os protestos das mulheres, podem ser as explicações para as mulheres "aceitarem" o comportamento de seus colegas de trabalho.

As narrativas do casal entrevistado foram extremamente importantes por evidenciarem que, já nas décadas de 40 e 50, havia atitudes na empresa, que refletiam a visão da sociedade sobre as mulheres, não as considerando como trabalhadoras, mas sim objeto sexual, imagem esta, bem evidente na pesquisa que realizei em 2001. Contudo, a postura de "se acostumarem" com tal comportamento se observou, em 2001, apenas nas áreas gerenciais e administrativas, na área produtiva as mulheres estavam muito insatisfeitas pelo tratamento recebido por seus colegas. Neste setor, os operários, com o intuito de estabelecer hierarquias, visto que o salário era o mesmo, se utilizavam de "cantadas" e exclusões destas nos processos seletivos internos, pois estes trabalhadores tinham autonomia de escolher com quem trabalhar. 
Ao realizar as entrevistas com trabalhadoras da área produtiva da fábrica em Vinhedo, verifiquei que havia uma séria inquietação por parte destas operárias no que se referia ao processo de seleção interno. A área produtiva, das fábricas do grupo anglo holandês, era constituída por núcleos de trabalho semi-autônomos, ou seja, estes grupos possuíam autonomia na escolha dos integrantes de seus núcleos. No início da formação destes núcleos, as escolhas foram realizadas pelos coordenadores de produção e, de acordo com relatos, havia pelo menos uma mulher em cada núcleo. Em um segundo momento, os próprios trabalhadores passaram a fazer estas escolhas e começaram a excluir todos aqueles que não faziam parte do círculo de amizades daquele núcleo que estava realizando o processo de seleção. Fazer parte do círculo de amizades significava, para os trabalhadores da fábrica estudada, saírem juntos para beber depois do trabalho, jogarem futebol juntos, isto é, possuir uma relação pessoal entre eles. Não estavam privilegiando, neste caso, a competência do trabalhador ou da trabalhadora, mas sim a "amizade" estabelecida entre o grupo e o candidato à vaga. A situação das trabalhadoras, nesta área, se tornava mais crítica, porque dificilmente fariam este tipo de programa com seus colegas homens, já que qualquer conversar entre os sexos opostos na fábrica era considerado, pelos operários, relacionamento pessoal. Por este motivo, os núcleos estavam preferindo, na maioria dos processos de seleção, trabalhadores homens para integrar o seu grupo de trabalho.

Muitas foram às justificativas dadas para a exclusão das mulheres dos núcleos. As mulheres eram excluídas, na opinião dos gerentes da produção, porque os homens consideram o trabalho muito "pesado" e argumentam que as mulheres "não dariam conta de executá-lo". Por isso, estavam optando, conforme comentários dos próprios trabalhadores da produção, por homens que trabalhassem bem - no sentido de darem conta das funções a serem executadas - e, que possuíssem certa afinidade, para que não ocorressem problemas de relacionamento no futuro. Como afirmou um dos entrevistados: Não vou trabalhar com quem eu não conheço e não sei se vou me dar bem com ele. Com isto acabava-se não 
| 198 |

Gênero e trabalho: as relações entre...

dando oportunidade para muitas mulheres que queriam e eram capazes de "dar conta" das funções a serem exercidas, e aos outros operários que eram competentes, contudo, não eram "conhecidos".

Diante de tais relatos chegou-se à conclusão, ao término da pesquisa realizada na fábrica em Vinhedo, que as denominadas "cantadas" foram utilizadas como um recurso, construído pelos operários, para excluírem simbolicamente suas colegas de trabalho, pois tal comportamento fazia com que estas se sentissem inferiorizadas, marcando uma diferenciação hierárquica entre eles. Como esta fábrica e sua filial em Pernambuco eram as únicas que possuíam mulheres na área produtiva, os operários encontraram uma maneira de igualarem-se às outras fábricas do grupo. As trabalhadoras realizaram uma excelente interpretação da situação vivenciada por elas: as exclusões e as "cantadas" eram instrumentos utilizados pelos trabalhadores para estigmatizá-las e assim manterem a "predominância masculina" na área produtiva da fábrica.

Na fábrica localizada em Valinhos, segundo narrativas de D. Maria e do Sr. José, comportamentos como "cantadas" recebiam punições exemplares. No entanto, as penalidades nesta fábrica, restringiam-se aos relacionamentos pessoais entre trabalhadores, não atingindo comportamentos, tais como os citados por D. Maria, nos quais o próprio chefe "convidava" os operários para observarem as peças íntimas de suas subordinadas.

Stolcke (1993), em uma pesquisa com famílias de camponeses, mostra que os homens não aceitavam muito bem que suas mulheres e filhas trabalhassem em espaços nos quais não estavam sob sua supervisão, principalmente em turmas de trabalhadores, visto que consideravam como "lugares de moral duvidosa, impróprias para mulheres respeitáveis" (Stolcke, 1993: 100). Na interpretação desta autora, os "turmeiros" - aqueles encarregados de contratarem mãode-obra para a agricultura - tinham fama, que não era infundada, de se aproveitarem de sua posição para seduzir as trabalhadoras. Esta suspeita era ainda reforçada, pela crença generalizada de que as mulheres que não têm proteção/supervisão de seus homens 
facilmente sucumbiriam às investidas de outros homens. Esta desconfiança era fruto da moralidade tradicional, que garantia aos homens direitos exclusivos à sexualidade de suas mulheres (o que requeria o controle destas), e do temor muito concreto das conseqüências que poderia ter o contato das mulheres com homens não-pertencentes à família, "homens de fora", para a sobrevivência desta. (STOLCKE, 1993, p. 100).

Pode-se perceber, a partir da citação de Stolcke, que o comportamento observado nas fábricas pesquisadas era uma maneira de manter a divisão sexual do trabalho, no qual o espaço público, do trabalho, era reservado apenas aos homens, às mulheres restava à esfera doméstica. Neste caso, aquelas que "ousassem" transgredir tais "regras", deveriam sofrer "punições", isto é, "cantadas" e "seduções". Assim, estas condutas se apresentavam como mais uma estratégia para "expulsar" as mulheres de um lugar ao qual "não pertencem", ou seja, o trabalho "fora de casa". Por isso, era comum à época, o incentivo para que as mulheres, ao se casarem, se demitirem de seus empregos, como será destacado adiante. Além disto, no momento em que há uma inserção maior destas no mercado de trabalho brasileiro, na década de 1970, momento da inauguração da fábrica em Vinhedo, o comportamento "sedutor" surge como inerente à administração da mesma, justificando até mesmo seus maus resultados no negócio, como evidenciou Barbosa (1996).

Desse modo, a questão sexual ao ser utilizada como exclusão simbólica, refletia, de certa maneira, a própria estrutura de divisão do trabalho estabelecida nas fábricas pesquisadas. É o que será exposto abaixo.

\section{A questão sexual e seus reflexos na divisão sexual do trabalho}

Durante a pesquisa na fábrica em Valinhos, todos os entrevistados foram unânimes ao afirmarem que até meados dos anos 80 , do século passado, as mulheres eram maioria na área 
| 200 |

Gênero e trabalho: as relações entre...

produtiva, fato este que muda drasticamente com a introdução de máquinas automatizadas. $\mathrm{O}$ argumento dado por esta empresa, e também por outras, seria que as mulheres eram mais aptas ao trabalho manual. O professor J. P. Porto-Carreiro (1930 apud Besse, 1999) ofereceu uma justificativa considerada por ele mais científica para a divisão entre trabalhos masculinos e femininos, cujo conteúdo é muito interessante para refletirmos, acerca dessa imagem das mulheres como objetos sexuais:

\begin{abstract}
A atitude psíquica do homem e da mulher são apenas o reflexo da sua atitude física na conjunção amorosa: um procura, estreita, penetra, possui; a outra atrai, abrese, entrega-se, recebe. O trabalho, pura sublimação de impulsos da vida, será sempre distribuído pelos sexos, de acordo com aquelas atitudes. (PORTO-CARREIRO, 1930 apud BESSE, 1999: 361).
\end{abstract}

Este professor ao dar suas explicações "científicas" para a divisão sexual do trabalho o faz, por meio de conotações sexuais: o homem "procura, possui", a mulher "atrai, recebe, entrega-se", aquele domina, este recebe, submete-se ao outro. Esta analogia é muito curiosa, pois põe em evidência a relação percebida em ambas as pesquisas entre a estrutura construída pela empresa na contratação de trabalhadores, privilegiando a divisão sexual do trabalho e, condutas dos trabalhadores, permeadas de insinuações e ações de caráter sexual.

Ao longo de sua narrativa, o Sr. José recordou-se de um fato, que demonstrava que houve situações em que se presenciou relações sexuais dentro da própria fábrica em Valinhos:

Posso contar em off isso, é uma figura, uma figura impávida. Também ele pagou pelo que ele fez. Mudou, lembra? Os produtos ia direto para o depósito onde... Retirava tudo lá na expedição 74 . Depois, eles passaram a retirar o sabonete embaixo, no porão, aí inventaram o tal de porão no sabonete um da fábrica. Embaixo tinha o sabonete um... Acho que não tinha 


\begin{abstract}
nem o sabonete dois, estava construindo. Inventaram o porão embaixo e de lá retiravam o produto direto e lá que cataram um monte de gente fazendo coisa que não devia lá embaixo, do dito porão lá do... Foram oito ou nove pessoas na época que estavam envolvidos nesse... Mudaram a retirada do produto, inventaram o porão lá do sabonete um, aí a turma tinha ojeriza de passar lá: Deus me livre ir nesse porão aí. Ninguém queria mais passar pelo porão.
\end{abstract}

Após este episódio todos os envolvidos foram demitidos, segundo o Sr. José. O filho deste entrevistado e, também alguns outros entrevistados atribuíram este tipo de conduta por haver, àquela época, um número de trabalhadoras superior ao de trabalhadores e acreditavam que esta situação deixou de ocorrer em Valinhos em função do número reduzido de mulheres na fábrica. Pelo mesmo motivo acreditam que ainda existam situações deste tipo em Vinhedo, isto é, por causa do grande número de mulheres naquela fábrica. Neste sentido, as explicações apresentadas, pelos entrevistados, como causa de comportamentos sexuais nas fábricas foram à quantidade de mulheres nas mesmas. Este fato nos conduz novamente à questão do caráter excludente de tais atitudes de cunho sexual, que tinham por finalidade "retirar" as mulheres do "lugar" que era considerado exclusivamente masculino. Os relatos de D. Maria e do Sr. José esclarecem que esse tipo de atitude não era algo recente e não ficou restrita a uma de suas fábricas, já que aparecem em ambas, em diferentes momentos e contextos.

Para embasar tal argumento, isto é, que as condutas adotadas pelos operários da empresa em questão objetivavam a exclusão das trabalhadoras da área da manufatura, quando realizei minha pesquisa em 2001, verifiquei que o número de mulheres na fábrica em Vinhedo não era mais do que $20 \%$ do total de trabalhadores. Em Valinhos a situação era ainda mais contundente, pois não havia mais mulheres na produção, embora no início das atividades da fábrica estas tenham sido maioria. Por este motivo, também questionei ao que atribuíam a diminuição do contingente feminino das fábricas e o Sr. José destacou sua opinião: Antigamente as moças 
| 202 |

Gênero e trabalho: as relações entre...

casavam e paravam de trabalhar, daí só trabalhava o marido, a mulher ficava em casa.

Sobre esta questão Besse (1999) esclarece que muitos críticos sociais consideravam o trabalho das mulheres um mal necessário, imposto pelas contingências da vida moderna, por isso se as mulheres deveriam trabalhar por salário, "isso devia ser temporário e incidental, e não central em sua vida e em seu pensamento". (BESSE, 1999, p. 147). Assim, a mulher ter um emprego ou possuir aspirações a constituir uma carreira merecia elogios apenas enquanto ela fosse solteira, ou "enquanto sua família estivesse necessitada, mas não como um sucedâneo de longo prazo das obrigações familiares". (Besse, 1999, p. 151). Desse modo, a expectativa era de que as mulheres se demitissem do emprego e desistissem de quaisquer aspirações de constituição de carreira ao garantirem o sustento com o casamento, como mostra o relato do Sr. José citado acima.

Este estímulo à desistência da carreira pelas mulheres era também criado por meio de estereótipos - o que é denominado por Stolcke (1980) de "ideologia burguesa" - dados às mulheres profissionais independentes, tais como, "mulheres-homem", "anomalias" e "erros da natureza". Rótulos como estes tinham como finalidade manter a dicotomia produção/reprodução, na qual a primeira seria "destinada" aos homens e a segunda, às mulheres. Colbari (1995) cita um trecho extraído da imprensa operária que exemplifica esta discussão: (...) “o papel da mulher não consiste em abandonar seus filhos em casa e ir para a fábrica trabalhar, pois tal abandono origina conseqüências lamentáveis" (...) (A RAZ̃̃O, 20/7/1917, apud Colbari, 1995, p. 30).

Além destes estereótipos, a própria segregação das mulheres em funções consideradas enfadonhas, sem atrativos e mal pagas, conforme esta autora contribuía para mantê-las econômica e emocionalmente dependentes de seus maridos e famílias.

Ao realizar um banco de dados sobre o trabalho das mulheres, Bruschini e Lombardi (1998) constatam que até a década de 1970, em sua maioria, as trabalhadoras eram jovens, solteiras e sem filhos. Nos anos 80 , esse perfil é alterado e há uma crescente 
introdução de mulheres mais velhas, casadas e mães. A justificativa para tal mudança, de acordo com estas autoras, estaria,

de um lado, como um indício da pressão econômica, que estava forçando mulheres com essas características a procurar o mercado de trabalho. A diversificação das pautas de consumo, gerando novas necessidades e desejos, o empobrecimento da classe média e a necessidade de arcar com os custos de educação e saúde, devido à precarização dos sistemas públicos de atendimento. (Bruschini e Lombardi, 1998, p. 165).

Estas autoras destacaram que, por outro lado, houve a expansão da escolaridade, à qual as mulheres começaram a ter cada vez mais, como outro fator que explicaria o aumento do número de mulheres casadas e mães no mercado de trabalho.

No caso de D. Maria, esta entrou para o mercado de trabalho quando era solteira por meio da indicação de uma colega que era encarregada da área produtiva da fábrica em Valinhos, no cargo de supervisora do trabalho das mulheres. Segundo seu relato, havia uma divisão sexual bem nítida no que se referia ao trabalho, isto é, os trabalhadores tinham como chefe um homem e as mulheres eram chefiadas também por uma mulher. Atualmente ainda há uma divisão sexual do trabalho na empresa, porém os cargos são distribuídos por características consideradas "mais femininas" ou "mais masculinas", os quais atribuem a homens e mulheres comportamentos ditos "naturais". No entanto, sabe-se que estes são construções sociais, tema discutido por vários autores, na área de gênero. Scott (1987), por exemplo, considera o conceito uma categoria analítica, que "possibilita a busca de significados das representações tanto do feminino quanto do masculino, inserindoas nos seus contextos culturais e históricos" (Scott, 1987, 1069). Na concepção da autora, a análise das questões de gênero também implica a análise das relações de poder. Nesse sentido, salienta que essa relação permite a apreensão de duas dimensões: 
| 204 |

Gênero e trabalho: as relações entre...

o gênero como elemento constitutivo das relações sociais, baseado nas diferenças perceptíveis entre os sexos; o gênero como forma básica de representar relações de poder em que as representações dominantes são apresentadas como naturais e inquestionáveis. (Scott, 1987, p. 1069).

Para Scott (1987), diferentemente de sexo, o gênero é um produto socialmente elaborado e representado, sendo que as diferenças entre os sexos seriam fundamentalmente culturais, estas entendidas como produções de indivíduos e coletividades. Esta autora ressalta ainda, que o desafio analítico proposto passa a ser o de identificar, em cada prática e relação social concreta, a produção tanto das subordinações como das formas de resistência nas questões de gênero. Ao observar as relações de poder estabelecidas, a partir de questões sexuais, que tinham o intuito de inferiorizar e excluir as operárias, foi adotado este conceito de gênero em ambas as pesquisas.

O comportamento dos operários destas fábricas refletia, segundo as narrativas do Sr. José, as próprias atitudes masculinas da nossa sociedade. Este senhor comenta que a porta da fábrica em questão era considerada, à época, ideal para encontrar uma namorada, pois só havia "moças bonitas e muito perfumadas", este último por causa do trabalho de embalagem de sabonetes realizados pelas operárias da fábrica. Esta narrativa, além de evidenciar a imagem que se tinha destas mulheres, destaca também que, naquele momento, a maioria dos trabalhadores da fábrica era composta por mulheres. Na concepção de Besse (1999), ao analisar a reestruturação da ideologia de gênero no Brasil nos anos de 1914 a 1940, as indústrias preferiam empregar as mulheres na fabricação de objetos que exigiam "fino tato" - características "naturais" das mulheres-, cujo argumento dos empregadores era a economia de somas consideráveis de dinheiro "contratando mulheres bemqualificadas por menos de dois terços do salário que teriam que pagar aos homens". (BESSE, 1999, p. 149).

Esta autora enfatiza ainda que, além da contratação de mulheres para trabalhos nos quais estas tivessem habilidades 
"naturais" tais como paciência, alegria, retidão moral, delicadeza, discrição, piedade, dedicação aos outros, destreza manual, atenção a detalhes mínimos, obediência às diretrizes dadas por chefes, entre outros, havia uma grande vantagem econômica para os empregadores.

As representações sobre as mulheres, descritas por Besse (1999), pode ter influenciado a contratação das mulheres na empresa pesquisada, naquele período histórico, mas também por ser esta uma empresa de sabonetes, na qual a diferenciação no mercado se dava, conforme dados da mesma, por suas "delicadas" embalagens, habilidades consideradas "naturais" às mulheres. Além disso, a escolha das trabalhadoras se dava também, de acordo com esta autora, segundo a idealização que os empresários e sociedade construíam sobre estas, ou seja, como "fiadoras da vida familiar estável e principais socializadoras das gerações futuras". (BESSE, 1999, p. 07). Desse modo, a inserção da mão-deobra feminina era extremamente vantajosa, já que além de eficiente era mais barata. O que se propagava era que as mulheres poderiam trabalhar desde que não comprometesse sua "feminilidade" (pureza, doçura, abnegação, espírito maternal, entre outros), nem ameaçasse a estabilidade do lar chefiada pelo homem, por isso, estimulavam a divisão sexual do trabalho. A segmentação por sexo no mercado de trabalho era encarada de modo geral, para Besse (1999), como o meio essencial para conciliarem necessidades econômicas e interesses sociais:

Na medida em que as mulheres fossem mantidas separadas em ocupações "femininas apropriadas", os empregadores, os parentes e os trabalhadores do sexo masculino poderiam esperar que a honestidade e a dignidade das mulheres não estaria comprometida, seus encantos femininos peculiares não seriam maculados e elas continuariam a ser complementares e dependentes dos homens, ao invés de alcançar sua independência. Obviamente, neste caso, não ameaçariam nem o ego nem os salários dos homens. (Besse, 1999, p. 154). 
| 206 |

Gênero e trabalho: as relações entre...

Nesse sentido, os homens continuariam provedores de suas famílias e não seriam ameaçados por suas mulheres, permanecendo assim a hierarquia entre os sexos.

Na interpretação de Stolcke (1980), as instituições que estão nas raízes da subordinação das mulheres na sociedade de classe são o casamento e a família, fato este que aparece nas narrativas do Sr. José e de D. Maria ao comentarem que as mulheres na década de 1940 e 50 tinham que optar entre trabalhar e construir uma carreira ou casar e desempenhar o papel que lhe era "natural", isto é, o trabalho doméstico.

Esta autora também sublinha que a crescente profissionalização das mulheres, na sociedade atual, não ameaçou a família nem as relações de propriedade existentes, visto que as mulheres continuam a ser definidas socialmente, em primeiro lugar, como mães, ou seja, "sua incorporação na 'produção' é determinada, em grande parte, pelas necessidades oscilantes do mercado de trabalho e não vista como um direito inerente". (Stolcke, 1980, p. 102).

A partir dos dados coletados nas narrativas apresentadas evidenciou-se que, mesmo após a reestruturação produtiva implantada pela empresa estudada, com máquinas mais automatizadas, continuou a se privilegiar as mulheres em áreas que ainda necessitavam do trabalho manual, as quais requeriam "delicadeza", por considerarem um atributo feminino, algo que também foi observado em pesquisa anterior (Muniz, 2001a) e por Amorim (2003), em sua pesquisa sobre o trabalho feminino em indústrias de confecção. Características como "meticulosidade", "delicadeza", "diligência" eram consideradas habilidades tipicamente femininas, as quais eram aprendidas no espaço familiar.

A pesquisa realizada em 2001 revelou também, após leituras de Hirata (2002), que esta empresa utilizava e reforçava a divisão sexual existente tanto na sociedade quanto nos espaços das fábricas, mesmo depois das mudanças na administração em Vinhedo. 
As transformações no mundo do trabalho provocadas pela denominada reestruturação produtiva ${ }^{5}$, conforme Segnini (1998) tem como uma de suas características a "feminização" do trabalho, sobretudo no setor terciário da economia. Segundo esta autora, baseada em algumas pesquisas realizadas sobre o assunto, principalmente a de Anne Lerrolle Doniol-Shaw, o motivo da ocorrência deste fato se deve às mulheres serem, no contexto de trabalho polivalente, 'campeãs de adaptabilidade'. Destaca que as novas exigências para este tipo de trabalho encontram nas mulheres disposição não negligenciável para aquisição de competências como o nível de escolaridade mais elevado que os dos homens em postos de trabalho semelhantes (conforme também observado nas pesquisas aqui apresentadas) e o fato 'das competências adquiridas na vida doméstica serem facilmente transferidas para estas novas situações de trabalho'. A autora salienta que a experiência cotidiana vivenciada, particularmente, pelas mulheres, da reconversão frente a diferentes papéis que se modificam sucessiva ou concomitantemente, vivenciados na vida privada, tendem a fortificar a capacidade de adaptação a mudanças. (Segnini, 1998, p. 173).

Dessa forma, as tarefas executadas pelas mulheres, no espaço privado, ao contrário de ser algo limitador para a mulher aparece como um elemento qualificador frente à possibilidade de ter adquirido socialmente habilidades requeridas para a realização do trabalho flexível, afirma Segnini (1998). Numa época na qual se dá, no mundo do trabalho, uma grande importância a polivalência, esta "habilidade" adquirida pela mulher no âmbito social, passa a ser também "apropriada", neste caso pelos empresários, na indústria, que passa a explorar mais esta "habilidade" das mulheres. Um "guru" empresarial americano em entrevista a Revista Exame confirma este fato: "Elas (as mulheres) são craques em fazer um monte de coisas ao mesmo tempo", explicitando a

\footnotetext{
${ }^{5}$ Antunes (1997) destaca que processo de reestruturação produtiva no Brasil, especialmente nos anos 90, caracterizou-se pela redução de custos por meio da diminuição da força de trabalho em vários setores industriais.
} 
polivalência como característica feminina. (REVISTA EXAME, 24/01/2001, p. 01).

O Sr. Ernani, um trabalhador aposentado da fábrica localizada em Valinhos, relatou que, na área produtiva desta fábrica, também havia muitas mulheres trabalhando, enquanto as máquinas eram manuais, porém, com a automação, este número foi se reduzindo, assim como em Vinhedo. Algo semelhante é discutido por Amorim (2003), ao afirmar que mesmo no ramo de confecção, que tem sido tradicionalmente composto por mulheres, "quando se trata da modernização de postos de trabalho que implique no aumento da qualificação dos seus ocupantes, em geral, são os homens que passam a ocupá-lo". (Amorim, 2003, p. 03).

Pollert (1996), ao pesquisar a fábrica Choc-Co, tradicional na Inglaterra na área de alimentos, esta também observa uma distinção entre áreas baseadas no sexo do trabalhador (a). Nas áreas de capital intensivo, no qual há um maior rigor tecnológico, predominam os homens e nas áreas de trabalho intensivo, que exige um maior trabalho "vivo" predominam as mulheres. Esta divisão de áreas foi considerada de certa forma irônica por esta pesquisadora, já que a área "nobre" da empresa, que possuía máquinas computadorizadas, embora ainda permanecessem algumas máquinas manuais, era freqüentemente chamada de "cozinha", local construído socialmente como pertencente às mulheres. As mulheres estariam concentradas fora da "cozinha", na embalagem, nas áreas de trabalho intensivo e repetitivo, reforçando as argumentações de que a polivalência das mulheres no trabalho doméstico, foi traço distintivo da inserção da força humana feminina na "era" da reestruturação produtiva. Essa divisão sexual do trabalho fica evidente, na fábrica pesquisada por Pollert conforme mostram seus dados, nas próprias máquinas que não são assexuadas, foram construídas para serem manuseadas por pessoas com estaturas mais altas, que se encaixa na maioria dos casos, aos homens. Outro fator distintivo relatado pelos trabalhadores desta fábrica, de acordo com a autora, que justificariam a exclusão das mulheres na área, são os banheiros que 
também são masculinos, mostrando que a área foi idealizada para que apenas homens a ocupassem.

Os dados coletados por Pollert (1996) legitimam a concepção de Bruschini (1998) sobre as conquistas de espaços pelas mulheres no mercado de trabalho não terem extinguindo as discriminações sofridas por estas neste mercado. Como Bruschini (1998) destaca as oportunidades para as mulheres, em comparação aos homens, são mais limitadas e as barreiras são maiores para ocupar cargos de chefia.

Estas questões ficam evidentes ao comparar-se o número de mulheres no início das atividades da fábrica em Valinhos, as quais eram maioria, com sua total ausência atualmente, em função da automação, segundo informações obtidas.

As únicas fábricas do grupo que ainda possuíam mulheres na produção eram as localizadas em Vinhedo- SP e Recife- PE, por esse motivo na pesquisada realizada em 2001, pôde-se observar que os operários estavam sentindo-se ameaçados por suas colegas de trabalho, pois consideravam a área produtiva como exclusivamente masculina. Desse modo, construíram mecanismos de exclusão destas mulheres da produção que foram denominadas de "cantadas" e, como podiam escolher os integrantes do grupo de trabalho na área, acabavam por dar preferência aos seus amigos do sexo masculino.

Pode-se aproximar essa necessidade dos operários da fábrica em Vinhedo de se destacarem das operárias, como o que Elias afirma ser, talvez, a necessidade humana, "nunca serenada, de elevar a auto-estima, de melhorar o valor da própria pessoa ou do próprio grupo", ao sentirem-se ameaçados a perderem espaço em uma área que é considerada "masculina". (Elias, 2000, p. 209).

Já na área administrativa da fábrica em Vinhedo, a questão das "cantadas" possuía uma conotação diferenciada. Durante a análise dos dados coletados pôde-se perceber que havia ainda representações sobre o passado de festas nesta área, sob uma forma de "brincadeira", cujo caráter sexual encontrava-se mais implícito. Neste caso, era "comum" os trabalhadores "elogiarem" os atributos sexuais de suas colegas de trabalho, sempre destacados como 
"brincadeiras", por isso não estas mulheres não consideravam este fato um problema, pois estavam "acostumadas" com este tipo comportamento de seus colegas, algo muito semelhante ao relatado por D. Maria anteriormente.

Em ambos os casos, a estratégia utilizada pelos trabalhadores apresentou-se como uma maneira de "expulsar" as mulheres de um lugar ao qual não pertenciam, ou seja, o trabalho "fora de casa". O intuito era preservar uma hierarquia entre os sexos, visto que os salários e funções eram iguais em todos os cargos da empresa. Dessa maneira, para adquirir certa superioridade em relação às trabalhadoras, os trabalhadores procuravam inferiorizálas excluindo-as dos núcleos e tratando-as como objetos sexuais e não como profissionais. Aqui há uma explícita relação de poder, na qual as mulheres eram consideradas invasoras de um espaço que não lhes pertenciam. No caso das décadas anteriores, como era esperado que as mulheres se demitissem ao contrair matrimônio, o caráter sexual do relacionamento na fábrica poderia mostrar a superioridade dos homens e submissão das mulheres. Os contextos relatados eram diferentes, porém o intuito era muito semelhante.

\section{Considerações finais}

Comparando com a pesquisa anterior (Muniz, 2001a), percebeu-se, em alguns relatos, o discurso da própria empresa, o qual afirmava que havia um excelente diálogo entre todos os níveis hierárquicos, aquela "comunhão quase mágica entre todos, patrões e empregados", da qual comenta Aktouf (1993). Entretanto, na prática, o que se observou foi uma exclusão enorme das mulheres no setor da produção, considerada uma área "masculina". Este fato proporcionou a "extinção" das operárias na fábrica em Valinhos e a exclusão das mesmas do processo de seleção interno na fábrica em Vinhedo. Embora tenha havido mudanças administrativas, na fábrica em Vinhedo - SP, esta não conseguiu "apagar" resquícios de um passado que estava interferindo na imagem desta junto 
ao grupo anglo-holandês: a questão do olhar sobre a mulher caracterizado pelos atributos sexuais e os critérios subjetivos de seleção.

A introdução de "novas" tecnologias de automação também contribuiu para a diminuição das mulheres, na área produtiva, da fábrica em Vinhedo, e sua total supressão em Valinhos, por ainda se privilegiar características consideradas "naturais" a ambos os sexos como fator de divisão dos cargos na empresa, ou seja, as mulheres são consideradas mais "aptas" a desenvolverem trabalhos manuais.

As narrativas do Sr. José e de D. Maria foram de suma importância, porque permitiram evidenciar como eram as relações entre homens e mulheres na empresa em questão e a própria condição da mulher, na década de 50 do século passado. As mulheres, naquele momento, por sua educação para serem obedientes e subservientes eram uma mão-de-obra valorizada pelos empresários, além dos baixos salários. Para não ameaçarem os postos ocupados pelos homens, as mulheres deveriam demitir-se ao contraírem o matrimônio, caso contrário, seriam ridicularizadas pela sociedade, a partir da construção de estereótipos e estigmatizações. Além disto, eram vistas como objetos sexuais, as quais poderiam ser "apreciadas" sem qualquer tipo de reclamação, mantendo-as, deste modo, em condições de inferioridade. Algo também encontrado em pesquisa anterior (2001), mesmo passado tanto tempo e com todas as mudanças provocadas por lutas sociais feministas.

É importante destacar que há estudos que mostram como os de Cockburn (1985) no setor de radiologia computadorizada na Inglaterra e os de Sonia Laranjeira (1992) no setor de programação de um banco estatal no Rio Grande do Sul, citados por Lorena Holzmann (2000), que registram melhores oportunidades de ascensão a posições mais qualificadas e socialmente mais valorizadas na integração da mulher no mercado de trabalho. Alguns trabalhos considerados "masculinos" começam a serem desempenhados por mulheres em algumas empresas, como no caso 
da empresa CSN que, em 2006, tinha uma mulher na presidência, e, atualmente temos uma mulher na presidência da República.

Esse pequeno avanço das mulheres no mundo do trabalho pode estar fazendo com que os trabalhadores se sintam ainda mais ameaçados, aqui a referência é especificamente sobre a empresa em questão, e tentem manter seu status quo se comportando de maneira com que as trabalhadoras se sintam objetos sexuais, para, desta forma, estabelecer uma hierarquia entre os sexos. Anteriormente este tipo de comportamento não era reprimido, porém com a necessidade de construção de uma nova imagem para a empresa, fez com que proibissem relacionamentos pessoais entre os trabalhadores e trabalhadoras de suas fábricas, mas as "cantadas" e "brincadeiras" vieram substituir as atitudes anteriormente praticadas em relação às trabalhadoras, com a diferença de que antes muitas não se "importavam" com tais condutas.

$\mathrm{O}$ que se concluiu foi que, tanto no passado, como no presente, as trabalhadoras das fábricas pesquisadas eram tratadas por meio de estereótipos pelos mesmos motivos: reproduzir a divisão sexual do trabalho construída para manter as mulheres no espaço doméstico.

\section{Bibliografia}

AKTOUF, O. O simbolismo e a cultura de empresa: dos abusos conceituais às lições empíricas In. Chanlat, J. F. (coord.). O indivíduo nas organizações: dimensões esquecidas. São Paulo: Atlas, 2 v. 1993.

AMORIM, E. R. A. A. No limite da Precarização? Terceirização e Trabalho Feminino na Indústria de Confecções. Dissertação de Mestrado, Instituto de Filosofia e Ciências Humanas, Unicamp. 2003.

ANTUNES, R. Fordismo, toyotismo e a cumulação flexível. In. Adeus ao trabalho? Ensaio sobre as Metamorfoses e a Centralidade 
do Mundo do Trabalho. 4 edição, São Paulo: Cortez, Ed. da UNICAMP, 1997.

BARBOSA, L. Análise Cultural: Elida Gibbs. In. Relatório de análise cultural realizado na fábrica e centro empresarial Elida Gibbs. 1996/97.

BESSE, S. K. Modernizando a desigualdade: reestruturação da ideologia de gênero no Brasil, 1914-1940. São Paulo: EDUSP.1999.

BRUSCHINI e LOMBARDI, M. R. Trabalho feminino no final do século XX In. Cadernos Pagu, Campinas, n. 17/18, p. 157-196. 2001/02.

COCKBURN, C. Play of power: women, men and equality initiatives in a trade union In. WRIGHT, Susan. Anthropology of Organizations, London: Rutledge.1994.

COLBARI, A. L. Ética do Trabalho: a vida familiar na construção da identidade profissional. São Paulo: Letras \& Letras/ Ed. da FCAA/UFES. 1994, 1995.

ELIAS, N. A Sociedade dos Indivíduos. Rio de Janeiro: Jorge Zahar Ed. 1994.

. e SCOTSON, J. L. Os Estabelecidos e os Outsiders, Rio de Janeiro: Jorge Zahar Editor. 2000.

GAGNEBIN, J. M. História e Narração em Walter Benjamin. Campinas: Editora da Unicamp. 1994.

HIRATA, H. Nova Divisão Sexual do Trabalho? Um olhar voltado para a empresa e a sociedade. São Paulo: Boitempo. 2002.

HOLZMANN, L. Notas sobre as condições da mão-de-obra feminina frente às inovações tecnológicas. Sociologias, Porto Alegre, ano 2, n. 4, jul/dez.2000.

KOFES, S. 1994. Experiências Sociais, Interpretações Individuais: História de vida, suas possibilidades e limites In. Cadernos Pagu, Campinas, (3). 1994. 
. Uma Trajetória, em Narrativas. Campinas: Mercado de Letras. 2001.

MUNIZ, C. R. a. As representações nativas do universo fabril: um estudo etnográfico. Dissertação de Mestrado, IFCH, UNICAMP. 2001.

. As Construções Simbólicas de Exclusão em uma fábrica no interior do Estado de São Paulo. Humanitas, Campinas, v. 4, n. 2, ago./dez. 2001b.

As representações sobre o trabalho a partir das narrativas de uma família de operários. Tese de Doutorado, IFCH, UNICAMP. 2006.

PISCITELLI, A. G. Tradição Oral, Memória e Gênero: Um comentário metodológico In. Cadernos Pagu, Campinas, n 1.1993.

POLLERT, A. Team Work' on the Assembly Line In. ACKERS, P. et all. The New Workplace and Trade Unionism, Rutledge, Londres. 1996.

REVISTA EXAME, 24/01/2001.

SCOTT, Joan. Women's history and the rewriting of history, in history. In. Farnham Christi, The impact of feminist research in Academy, Indiana University Press/Bloomington/Indianapolis, 1987.

SEGNINI, L. Mulheres no Trabalho Bancário: Difusão Tecnológica, Qualificação e Relações de Gênero. São Paulo: Editora da Universidade de São Paulo, 1998.

SILVA, R. H. A. da. A Construção da Memória e as Lembranças de Moradores In SIMSON, O. R. de M. V. (org.). Os desafios contemporâneos da história oral. Campinas:CMU/Unicamp. 1996. 
STOLCKE, V. Mulheres e Trabalho In. Estudos CEBRAP, São Paulo, CEBRAP/Vozes, n. 26.1980.

. A Família que não é Sagrada In. ARANTES, A. A. (et al.). Colcha de Retalhos: estudo sobre família no Brasil. Campinas: Editora da Unicamp. 1993.

\section{Outras fontes}

DIRETOR DE RECURSOS HUMANOS. Mulher e Trabalho. Campinas, 18/10/1999. PROPÓSITO CORPORATIVO DO GRUPO ANGLO-HOLANDÊS. Inglaterra: Corporative Relations Department, 18/junho, 1997. 